\title{
Penerapan 5S (seiri, seiton, seiso, seiketsu, shitsuke) guna mengurangi waktu kerja di UKM keripik tempe
}

\author{
Tri Ernita ${ }^{1)^{*}}$, Riko Ervil ${ }^{2)}$, Melsa Fatjri Oktaviani ${ }^{3)}$ \\ ${ }^{123}$ Sekolah Tinggi Teknologi Industri Padang, Jln. Prof. Dr. Hamka No. 121 Tabing, Padang, Indonesia \\ triernita@yahoo.co.id*,rikopdg@yahoo.com,melsafatjrioktaviani@gmail.com
}

\begin{abstract}
ABSTRAK
Keripik Tempe Matahari adalah UKM yang bergerak di industri keripik tempe. Menciptakan lingkungan kerja yang bersih dan nyaman sangat berguna bagi UKM itu sendiri agar dapat mengoptimalkan suatu pekerjaan.Masalah yang terjadi masih adanya barang yang digunakan ditaruh disembarangan tempat, belum efisien waktu kerja yang dibutuhkan, dan barang yang belum diletakkan sesuai fungsinya. Penelitian ini betujuan untuk menerapkan metode 5S (Seiri, Seiton, Seiso, Seiketsu, Shitsuke) dan perbaikan waktu kerja dengan melakukan uji keseragaman data, uji kecukupan data, dan waktu baku. Hasil dari penelitian ini, pada penerapan metode 5S terdapat perubahan waktu kerja proses, dimana sebelum penerapan 5S (Seiri, Seiton, Seiso, Seiketsu. Shitsuke) adalah 4340 detik dan setelah penerapan metoda5S (Seiri, Seiton, Seiso, Seiketsu, Shitsuke)adalah 4086.03 detik dengan selisih sebanyak 253.97 detik atau 4.23 menit.
\end{abstract}

Kata kunci: 5S, waktu kerja proses, waktu baku

\begin{abstract}
Keripik Tempe Matahari is a UKM which is engaged in the tempe chips industry. Creating a clean and comfortable work environment is very useful for UKM themselves in order to optimize a job. The problem that occurs is that the items used are placed scattered, the work time required is not efficient, and the items are not placed according to their function. This study aims to apply the 5S (Seiri, Seiton, Seiso, Seiketsu, Shitsuke) method and improve working time by conducting data uniformity tests, data adequacy tests, and standard time. The results of this study, in the application of $5 S$ (Seiri, Seiton, Seiso, Seiketsu, Shitsuke) there was a change in the working time of the process, where before the implementation of $5 S$ was 4340 seconds and after the implementation of 5S (Seiri, Seiton, Seiso, Seiketsu, Shitsuke) was 4086.03 seconds with a difference of 253.97 seconds or 4.23 minutes.
\end{abstract}

Keywords: $5 S$, work process time, standard time

diunggah: November 2021, direvisi: Desember 2021, diterima: Desember 2021, dipublikasi: Desember 2021 Copyright (c) 2021 Tri Ernita, Riko Ervil, Melsa Fatjri Oktaviani

This is an open access article under the CC-BY license

\section{PENDAHULUAN}

Keripik tempe matahari merupakan UKM yang bergerak di industri keripik, Untuk melakukan proses produksi tersebut pihak UKM membagi kegiatan produksi sesuai dengan yang di produksi. Pada proses produksi Tempe ini terdapat lantai produksi yang tidak rapi dan berserakan, peralatan yang tidak digunakan masih berserakan di sembarang tempat. Dalam keadaan ini pekerja akan membutuhkan waktu sedikit lama dalam mengambil barangbarang yang akan digunakan.

Dengan masalah yang ada pada UKM keripik tempe maka di perlukan penerapan $5 \mathrm{~S}$ untuk mengurangi waktu kerja, metoda 5S (Seiri, Seiton, Seiso, Seiketsu, Shitsuke) sendiri memiliki dampak yang baik bagi Usaha Kecil Menengah (UKM) Kripik Tempe yang telah menerapkannya dimana dari segi waktu maka Usaha Kecil Menengah (UKM) tersebut dapat 
meminimalisasai waktu yang akan digunakan untuk pembuatan tempe, dan untuk produktivitas karyawan mereka harus memilah milah barang yang tidak tepakai lagi.

Kemajuan suatu perusahaan pasti diinginkan oleh pihak perusahaan manapun, tidak terkecuali Usaha Kecil Menengah (UKM) Keripik Tempe ini. Dan dengan diterapkan metoda 5S (Seiri, Seiton, Seiso, Seiketsu, Shitsuke) ini dapat di lakukan dengan cara meletakkan barang-barang yang memiliki fungsi yang sama, tidak berantakan dan meletakkan pada tempatnya, kebersihan harus diterapkan karena akan memberikan dampak positif bagi pihak Usaha Kecil Menengah Usaha Kecil Menengah (UKM).

5S (Seiri, Seiton, Seiso, Seiketsu, Shitsuke) merupakan budaya tentang bagaimana seseorang memerlakukan tempat kerjanya secara benar. Bila tempat kerja tertata rapi, bersih, dan tertib, maka kemudahan bekerja perorangan dapat diciptakan, dan dengan demikian 4 bidang sasaran pokok industri, yaitu efisiensi, produktivitas, kualitas, dan termasuk keselamatan dan kesehatan kerja akan dapat lebih mudah dicapai.

Tujuan dalam penelitian ini adalah untuk menerapkan metode 5S (Seiri, Seiton, Seiso, Seiketsu, Shitsuke) di Usaha Kecil Menengah Usaha Kecil Menengah (UKM). Keripik tempe serta untuk menghitung waktu kerja yang dibutuhkan setelah diterapkan 5S (Seiri, Seiton, Seiso, Seiketsu, Shitsuke).

\section{METODE}

Penelitian ini dilakukan di Jorong Panjang Bintungan 4 Blok D Sitiung 1. Kegiatan yang diamati disini adalah kegiatan pembuatan keripik tempe. Studi lapangan yang dilakukan pada penelitian ini adalah sebagai berikut :

Dokumentasi dilakukan untuk pengumpulan data yang ditunjukkan pada penjelasan melalui sumber-sumber dokumen (foto dan gambar) pada saat kondisi sebelum dan sesudah diterapkan metoda (Seiri, Seiton, Seiso, Seiketsu, Shitsuke) 5S.

Pengukuran dengan melakukan pengukuram waktu proses kerja pada pembuatan keripik tempe, dengan menggunakan jam henti kemudian data tersebut akan diolah dengan beberapa tahapan untuk memperoleh waktu baku. Waktu yang diambil pada proses kerja pembuatan keripik tempe yaitu waktu pembukaan bungkus tempe, pengadukan tepung, penggorengan, pendinginan, dan packing.

\section{HASIL DAN PEMBAHASAN}

Dari pengumpulan data diperoleh dokumentasi dan dilakukan pengukuran waktu kerja serta penarapan 5S di UKM sebagai berikut:

\section{Penerapan 5S}

1. Penerapan Seiri (Ringkas)

Adapun penerapan seiri di UKM kripik tempe pada stasiun pengadukan tepung yaitu menyingkirkan barang- barang yang tidak diperlukan, seperti menyingkirkan karduskardus, plastik-plastik, panci kukusan, dan saringan. Berikut gambar penerapan seiri sesudah diterapkan $5 \mathrm{~S}$ :

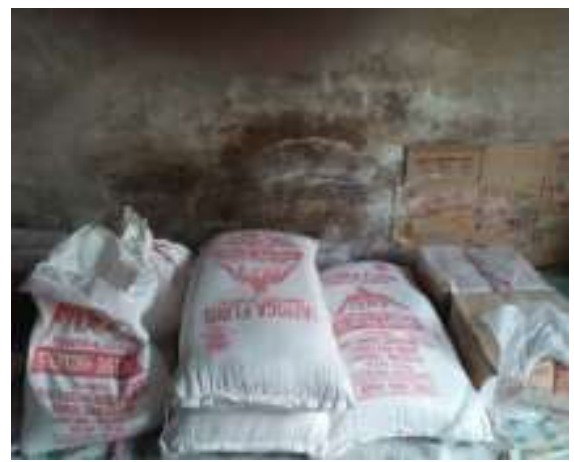

Gambar 1. Kondisi sesudah penerapan seiri 
2. Penerapan Seiton (Rapi)

Adapun penerapan seiton di UKM kripik tempe pada stasiun pengadukan tepung yaitu mengatur letak tepung sesuai dengan fungsinya dan tepung tidak ditumpuk dengan barang yang tidak digunakan, agar mudah mengambil, dan meletakkannya kembali ke tempat semula.

3. Penerapan Seiso (Resik)

Adapun penerapan seiso di UKM kripik tempe pada stasiun pembukaan bungkus tempe yaitu menyediakan sarana kebersihan di area kerja seperti menyediakan tempat untuk bugkus tempe agar tidak berserakan dilantai, dan langsung memisahkan bungkus tempe yang tidak digunakan dengan yang akan digunakan kembali.

4. Penerapan Seiketsu (Rawat)

Menerapkan dan mempertahankan seiri, seiton, dan seiso di stasiun pembukaan bungkus tempe dan pengadukan tepung dengan menjaga kondisi tempat kerja agar tetap rapih dan bersih, seperti selalu membuang barang-barang yang tidak digunakan lagi agar lebih memudahkan ketika ingin mengambilnya dan area kerja terlihat lebih bersih dan tertata baik.

5. Penerapan Shitsuke (Rajin)

Penerapan Shitsuke pada stasiun pembukaan bungkus tempe dan pengadukan tepung yaitu membiasakan untuk menerapkan seiri, seiton, dan seiso dengan melakukan pembersihan setiap selesei bekerja dengan membuang barang-barang yang tidak digunakan dan meyediakan tempat untuk menaruh bugkus tempe agar tidak berserahan di lantai. Selalu meningkatkan kedisiplinan dan diberikan arahan.

\section{Pengukuran waktu kerja masing-masing pembuatan keripik tempe}

Pengukuran ini menggunakan tingkat keyakinan 95\% dan tingkat ketelitian $10 \%$.

Berikut ini adalah perhitungan waktu kerja pembuatan keripik tempe:

1. Pembukaan Bungkus Tempe

Dari hasil rekapitulasi data pambuatan kripik tempe pada tahap pembukaan bungkus tempe didapat data dalam bentuk sub grup. Berikut data sub grub perhitungan pembukaan bungkus tempe :

Tabel 1. Perhitungan pembukaan bungkus tempe

\begin{tabular}{|c|c|c|c|c|c|c|c|}
\hline Sub Grup Ke & X1 & $\mathbf{X} 2$ & $\mathbf{X 3}$ & X4 & X5 & $\mathbf{x i}$ & $\mathbf{x}$ \\
\hline 1 & 585 & 582 & 586 & 583 & 587 & 2923 & 584.60 \\
\hline 2 & 582 & 587 & 588 & 587 & 585 & 2929 & 585.80 \\
\hline 3 & 586 & 584 & 584 & 582 & 588 & 2924 & 584.80 \\
\hline 4 & 583 & 586 & 587 & 580 & 584 & 2920 & 584.00 \\
\hline 5 & 582 & 585 & 582 & 585 & 585 & 2919 & 583.80 \\
\hline 6 & 580 & 589 & 584 & 590 & 587 & 2930 & 586.00 \\
\hline \multicolumn{5}{|c|}{ Jumlah } & & 17545 & 3509.00 \\
\hline
\end{tabular}

Dari tebel di atas terdapat perhitungan pembukaan bungkus tempe yang dibagi menjadi 6 sub grup. Pada sub grup pertama terdapat rata-rata 584.60 pada sub grub kedua terdapat rata-rata 585.80, pada sub grup ketiga terdapat rata-rata 584.80, pada sub grub keempat terdapat rata-rata 584.00, pada sub grub kelima terdapat rata-rata 583.80, pada sub grub keenam terdapat rata-rata 586.00, dengan total waku 3509.00 .

Dari data di atas dapat dicari uji kecukupan, uji keseragaman data dan waktu baku dapat dilihat pada langkah-langkah berikut.

a. Perhitungan harga rata-rata dari harga rata-rata sub grup

$$
\begin{aligned}
\overline{\bar{\chi}} & =\frac{\sum X I}{K} \\
& =\frac{3509}{6}
\end{aligned}
$$


$=584.83$ detik

b. Menghitung standar deviasi sebenarnya dari waktu penyelesaian

$$
\begin{aligned}
\sigma & =\frac{\sqrt{\sum(x i-x)^{2}}}{N-1} \\
& =\frac{\sqrt{(585.584 .83))^{2}+(582.5855 .85)^{2}+(586.584 .83)^{2}+\ldots \ldots \ldots \ldots \ldots \ldots \ldots \ldots \ldots . . . \ldots}}{30-1}+(587.584 .85)^{2} \\
& =2.59
\end{aligned}
$$

c. Hitung standar deviasi dari distribusi harga rata-rata sub grup

$$
\begin{aligned}
\sigma \overline{\bar{\chi}} & =\frac{\sigma}{\sqrt{n}} \\
& =\frac{2.59}{\sqrt{6}} \\
& =1.06
\end{aligned}
$$

d. Uji keseragaman data

\begin{tabular}{|c|c|c|c|c|}
\hline Pengamatan & Waktu & BKA & BKB & Rata-rata \\
\hline 1 & 585 & 588.01 & 581.66 & 584.83 \\
\hline 2 & 582 & 588.01 & 581.66 & 584.83 \\
\hline 3 & 586 & 588.01 & 581.66 & 584.83 \\
\hline 4 & 583 & 588.01 & 581.66 & 584.83 \\
\hline 5 & 582 & 588.01 & 581.66 & 584.83 \\
\hline 6 & 580 & 588.01 & 581.66 & 584.83 \\
\hline 7 & 582 & 588.01 & 581.66 & 584.83 \\
\hline 8 & 587 & 588.01 & 581.66 & 584.83 \\
\hline 9 & 584 & 588.01 & 581.66 & 584.83 \\
\hline 10 & 586 & 588.01 & 581.66 & 584.83 \\
\hline 11 & 585 & 588.01 & 581.66 & 584.83 \\
\hline 12 & 589 & 588.01 & 581.66 & 584.83 \\
\hline 13 & 586 & 588.01 & 581.66 & 584.83 \\
\hline 14 & 588 & 588.01 & 581.66 & 584.83 \\
\hline 15 & 584 & 588.01 & 581.66 & 584.83 \\
\hline 16 & 587 & 588.01 & 581.66 & 584.83 \\
\hline 17 & 582 & 588.01 & 581.66 & 584.83 \\
\hline 18 & 584 & 588.01 & 581.66 & 584.83 \\
\hline 19 & 583 & 588.01 & 581.66 & 584.83 \\
\hline 20 & 587 & 588.01 & 581.66 & 584.83 \\
\hline 21 & 582 & 588.01 & 581.66 & 584.83 \\
\hline 22 & 580 & 588.01 & 581.66 & 584.83 \\
\hline 23 & 585 & 588.01 & 581.66 & 584.83 \\
\hline 24 & 590 & 588.01 & 581.66 & 584.83 \\
\hline 25 & 587 & 588.01 & 581.66 & 584.83 \\
\hline 26 & 585 & 588.01 & 581.66 & 584.83 \\
\hline 27 & 588 & 588.01 & 581.66 & 584.83 \\
\hline 28 & 584 & 588.01 & 581.66 & 584.83 \\
\hline 29 & 585 & 588.01 & 581.66 & 584.83 \\
\hline 30 & 587 & 588.01 & 581.66 & 584.83 \\
\hline
\end{tabular}

$$
\begin{aligned}
\mathrm{BKA} & =\overline{\bar{\chi}}+3 \sigma \overline{\bar{\chi}} \\
& =584.83+3(1.06) \\
& =588.01 \text { detik } \\
\mathrm{BKB} & =\bar{\chi}-3 \sigma \bar{\chi} \\
& =584.83-3(1.06) \\
& =581.66 \text { detik }
\end{aligned}
$$

Dari hasil pengukuran di atas maka rekapitulasi nilai rata-rata, nilai BKA dan BKB sebagai berikut:

Tabel 2. Rekapitulasi hasil perhitungan data pada tahap pembukaan bungkus

tempe

Dari uji keseragaman data di atas pada tahap pembukaan bungkus tempe terdapat nilai BKA yaitu 588.01, BKB 581.66 dan rata-rata 584.83. Dari data di atas terdapat 
waktu kerja yang di luar batas kendali, sehingga dikatakan tidak seragam, dapat dilihat pada gambar berikut:

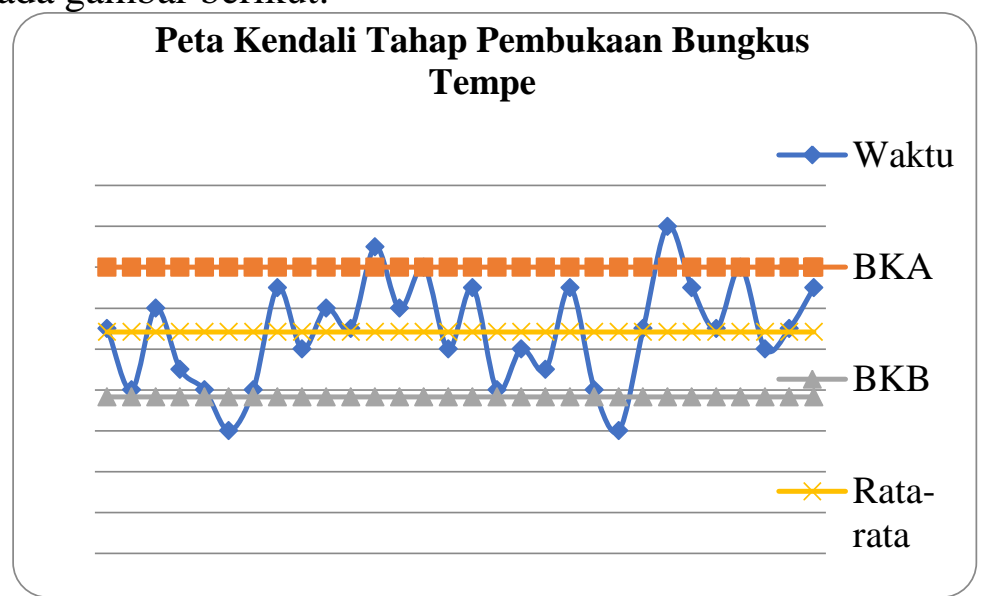

Gambar 2. Peta kendali pembukaan bungkus tempe

Dari peta kendali di atas terdapat data di luar batas kendali, maka terdapat beberapa yang harus dihilangkan. BKA sebanyak 2 data yaitu data ke 6, 22 dan BKB sebanyak 2 sata yaitu data ke 12, 24 maka data-data tersebut tidak bisa digunakan untuk uji kecukupan data.

Tabel 3. Rekapitulasi hasil perhitungan uji keseragaman data tahap pembukaan bungkus tempe yang seragam

\begin{tabular}{|c|c|c|c|c|}
\hline Pengamatan & Waktu & BKA & BKB & Rata-rata \\
\hline 1 & 585 & 588.01 & 581.66 & 584.83 \\
\hline 2 & 582 & 588.01 & 581.66 & 584.83 \\
\hline 3 & 586 & 588.01 & 581.66 & 584.83 \\
\hline 4 & 583 & 588.01 & 581.66 & 584.83 \\
\hline 5 & 582 & 588.01 & 581.66 & 584.83 \\
\hline 6 & 582 & 588.01 & 581.66 & 584.83 \\
\hline 7 & 587 & 588.01 & 581.66 & 584.83 \\
\hline 8 & 584 & 588.01 & 581.66 & 584.83 \\
\hline 9 & 586 & 588.01 & 581.66 & 584.83 \\
\hline 10 & 585 & 588.01 & 581.66 & 584.83 \\
\hline 11 & 586 & 588.01 & 581.66 & 584.83 \\
\hline 12 & 588 & 588.01 & 581.66 & 584.83 \\
\hline 13 & 584 & 588.01 & 581.66 & 584.83 \\
\hline 14 & 587 & 588.01 & 581.66 & 584.83 \\
\hline 15 & 582 & 588.01 & 581.66 & 584.83 \\
\hline 16 & 584 & 588.01 & 581.66 & 584.83 \\
\hline 17 & 583 & 588.01 & 581.66 & 584.83 \\
\hline 18 & 587 & 588.01 & 581.66 & 584.83 \\
\hline 19 & 582 & 588.01 & 581.66 & 584.83 \\
\hline 20 & 585 & 588.01 & 581.66 & 584.83 \\
\hline 21 & 587 & 588.01 & 581.66 & 584.83 \\
\hline 22 & 585 & 588.01 & 581.66 & 584.83 \\
\hline 23 & 588 & 588.01 & 581.66 & 584.83 \\
\hline 24 & 584 & 588.01 & 581.66 & 584.83 \\
\hline 25 & 585 & 588.01 & 581.66 & 584.83 \\
\hline 26 & 587 & 588.01 & 581.66 & 584.83 \\
\hline
\end{tabular}

Berdasarkan tabel di atas terdapat 26 data telah seragam. Data telah seragam dapat dilihat pada peta kendali berikut: 


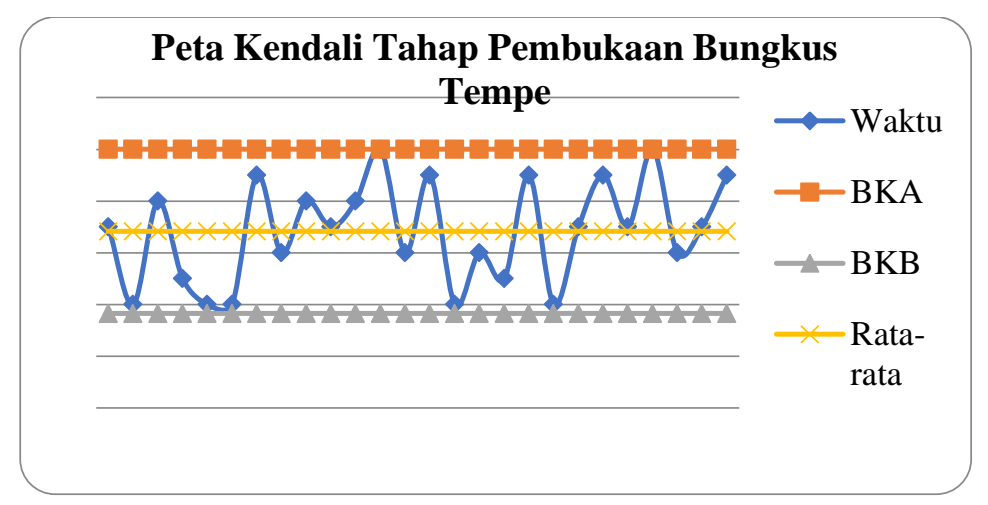

\section{Gambar 3. Peta kendali tahap pembukaan bungkus tempe yang seragam}

Dari peta kendali di atas dapat dilihat bahwa keseluruhan data telah berada di dalam batas kendali dan data dikatakan seragam, sehingga dapat dilanjutkan untuk uji kecukupan data.

e. Uji kecukupan data

Uji kecukupan data dapat dilihat pada tebel berikut:

\section{Tabel 4. Uji kecukupan data pembukaan bungkus tempe}

\begin{tabular}{|c|c|c|c|c|c|c|c|c|c|c|c|c|c|}
\hline \multicolumn{4}{|c|}{ Data } & \multirow{2}{*}{\multicolumn{2}{|c|}{ [XI }} & \multirow{2}{*}{$\left.(2 X I)^{M}\right)$} & \multicolumn{6}{|c|}{ XIM! } & \multirow[t]{2}{*}{ 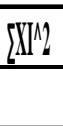 } \\
\hline Sub Gritup & \begin{tabular}{|l|l|} 
XI & . \\
\end{tabular} & 13 & XA & & & & Sub Grup Ke & X1 & X2 & $X 3$ & XA & 85 & \\
\hline 1 & 58558 & 584 & 582 & 852 & \multirow{7}{*}{\multicolumn{2}{|c|}{231222436}} & 1 & 342225 & 345669 & 341056 & 338724 & 342225 & 1708799 \\
\hline 2 & 58258 & 587 & 585 & 2 & & & 2 & 388724 & 341056 & 345609 & 342225 & 345609 & 1711143 \\
\hline 3 & 58658 & 582 & 587 & 2 & & & 3 & 343396 & 343906 & 338724 & 34560 & & 1370085 \\
\hline 4 & 58358 & 584 & 585 & 2 & & & 4 & 399889 & 342215 & 341056 & 342225 & & 1365395 \\
\hline$j$ & 58258 & 583 & 588 & 2 & & & j & 338724 & 343996 & 339889 & 35754 & & 136753 \\
\hline 6 & 58258 & 587 & 584 & 2 & & & 6 & 338724 & 345744 & 34560 & 341056 & & 1370093 \\
\hline & Totar & & & & 6016 & & & & Total & & & & 8893668 \\
\hline
\end{tabular}

Perhitungan uji kecukupan data dapat dilihat sebagai berikut:

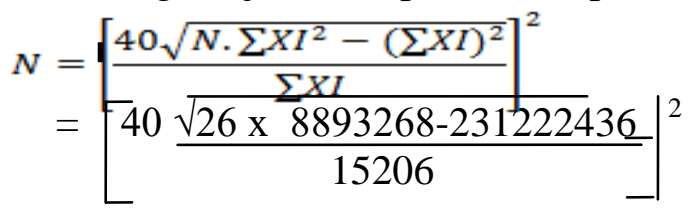$$
=0,09
$$

Berdasarkan perhitungan di atas, terdapat $\mathrm{N}>\mathrm{N}^{\prime}$ maka data dinyatakan cukup.

f. Perhitungan waktu siklus

Perhitungan waktu siklus dapat dilihat sebagai berikut:

$$
\begin{aligned}
\mathrm{WS} & =\frac{\sum X I}{N} \\
& =\frac{3509}{6} \\
& =584.83 \text { detik }
\end{aligned}
$$

g. Perhitungan waktu normal

Untuk mencari waktu normal maka tentukan terlebih dahulu faktor penyesuaiannya.

Perhitungan Faktor Penyesuaian sebagai berikut: 
Tabel 5. Faktor penyesuaian

\begin{tabular}{|l|c|c|c|}
\hline \multicolumn{5}{|c|}{ Rating Faktor } \\
\hline \multicolumn{1}{|c|}{ Faktor } & Kelas & Lambang & Penyesuaian \\
\hline Keterampilan & Good & C1 & 0.04 \\
\hline Usaha & Average & D & 0 \\
\hline Kondisi & Poor & F & -0.05 \\
\hline Konsistensi & Average & D & 0 \\
\hline \multicolumn{4}{|c|}{ Jumlah } \\
\hline
\end{tabular}

Dari tabel di atas terdapat faktor penyesuaian -0.01 jadi nilai $\mathrm{P}$ adalah:

$$
\begin{aligned}
\mathrm{P} \quad & =1-0.01 \\
& =0.99 \\
\mathrm{Wn}= & \text { Ws X p } \\
= & 584.83 \times 0.99 \\
= & 578.98 \text { detik }
\end{aligned}
$$

h. Perhitungan waktu baku

Perhitungan waktu baku dan perhitungan kelonggaran sebagai berikut:

Tabel 6. Faktor kelonggaran pembukaan bungkus tempe

\begin{tabular}{|c|l|c|}
\hline No & \multicolumn{1}{|c|}{$\begin{array}{c}\text { Faktor Yang } \\
\text { Mempengaruhi }\end{array}$} & \% Kelonggaran \\
\hline 1 & Tenaga yang Dikeluarkan & 8 \\
\hline 2 & Sikap Kerja & 2 \\
\hline 3 & Gerakan Kerja & 2 \\
\hline 4 & Pencahayaan & 5 \\
\hline 5 & Keadaan Suhu & 5 \\
\hline 6 & Keadaan Atmosfer & 0 \\
\hline 7 & Keadaan Lingkungan & 1 \\
\hline \multicolumn{2}{|c|}{ Total } & 23 \\
\hline
\end{tabular}

Dari tabel di atas terdapat bahwa faktor kelonggaran adalah $23 \%$,dan karena hambatan yang terhindarkan adalah 5\% maka waktu kelonggaran untuk itu adalah:

$(23 \%+5 \%)=28 \%=0.28$

$\mathrm{Wb}=\mathrm{Wn}+(1+\ell)$

$\mathrm{Wn}=578.98$ detik

$\ell=0.28$

$\mathrm{Wb}=578.98+(1+0.28)$

$=580.26$ detik

Dari hasil perhitungan di atas, maka didapat nilai rata-rata 584.83 detik, standar deviasi 2.59 detik, standar deviasi rata-rata sub grup 1.06 detik, nilai BKA 588.01 detik, BKB 581.66 detik, N'0.09, Ws 584.83 detik, Wn 578.99 detik, Wb 580.26 detik.

\begin{tabular}{|c|c|c|c|c|c|c|c|}
\hline Sub Grup Ke & X1 & $\mathbf{X} 2$ & $\mathbf{X 3}$ & X4 & $\mathbf{X 5}$ & $\mathbf{x i}$ & $\mathbf{x}$ \\
\hline 1 & 242 & 245 & 244 & 245 & 243 & 1219 & 243.80 \\
\hline 2 & 243 & 243 & 247 & 242 & 244 & 1219 & 243.80 \\
\hline 3 & 245 & 245 & 245 & 243 & 241 & 1219 & 243.80 \\
\hline 4 & 242 & 244 & 244 & 247 & 246 & 1223 & 244.60 \\
\hline 5 & 244 & 242 & 241 & 244 & 245 & 1216 & 243.20 \\
\hline 6 & 243 & 243 & 243 & 245 & 243 & 1217 & 243.40 \\
\hline \multicolumn{6}{|c|}{ Jumlah } & 7313 & 1462.60 \\
\hline
\end{tabular}

2. Pengadukan tepung

Dari hasil rekapitulasi data pambuatan kripik tempe pada tahap pengadukan tepung didapat data dalam bentuk sub grup sebagai berikut:

\section{Tabel 7. Perhitungan Pengadukan Tepung}

Dari tebel di atas terdapat perhitungan pengadukan tepung yang dibagi menjadi 6 sub grup. Pada sub grup pertama terdapat rata-rata 243.80, pada sub grub kedua terdapat ratarata 243.80 , pada sub grup ketiga terdapat rata-rata 243.00 , pada sub grub keempat terdapat rata-rata 244.60 , pada sub grub kelima terdapat rata-rata 243.60 pada sub grub keenam terdapat rata-rata 243.40, dengan total waku 1463.20. 
Dari data di atas dapat dicari uji kecukupan, uji keseragaman data dan waktu baku dapat dilihat pada langkah-langkah berikut:

a. Perhitungan harga rata-rata dari harga rata-rata sub grup

$$
\begin{aligned}
\bar{\chi} & =\frac{\sum X I}{K} \\
& =\frac{1462.60}{6}
\end{aligned}
$$

$=243.77$ detik

b. Menghitung standar deviasi sebenarnya dari waktu penyelesaian

$$
\sigma=\underline{\sqrt{\sum(x i-x)^{2}}}
$$

$$
=1.55^{N-1}
$$

c. Hitung standar deviasi dari distribusi harga rata-rata sub grup

$$
\begin{aligned}
\sigma \overline{\bar{\chi}} & =\frac{\sigma}{\sqrt{n}} \\
& =\frac{1.55}{\sqrt{6}} \\
& =0.63
\end{aligned}
$$

d. Uji keseragaman data

$$
\begin{aligned}
\mathrm{BKA} & =\overline{\bar{\chi}}+3 \sigma \overline{\bar{\chi}} \\
& =243.77+3(0.63) \\
& =245.66 \mathrm{detik} \\
\mathrm{BKB} & =\bar{\chi}-3 \sigma \overline{\bar{\chi}} \\
& =241.87-3(0.63) \\
& =241.87 \text { detik }
\end{aligned}
$$

Dari uji keseragaman data di atas pada tahap pengadukan tepung terdapat nilai BKA yaitu 245.66, BKB 241.87 dan rata-rata 243.77. Dari data di atas terdapat waktu kerja yang diluar batas kendali, sehingga dikatakan tidak seragam.

Dari peta kendali di atas terdapat data diluar batas kendali, maka terdapat beberapa yang harus dihilangkan.

e. Uji kecukupan data

Perhitungan uji kecukupan data ${ }_{2}$ dapat dilihat sebagai berikut:

$$
\begin{aligned}
N & =\left[\frac{40 \sqrt{N \cdot \sum X I^{2}-\left(\sum X I\right)^{2}}}{\sum X I}\right]^{2} \\
& =\left[\frac{40 \sqrt{25 \times 1484039-37100281}}{6091}\right]^{2} \\
& =0.06
\end{aligned}
$$

Berdasarkan perhitungan di atas, terdapat $\mathrm{N}>\mathrm{N}^{\prime}$ maka data dinyatakan cukup.

f. Perhitungan waktu siklus

Perhitungan waktu siklus dapat dilihat sebagai berikut:

$$
\begin{aligned}
\mathrm{WS} & =\frac{\sum X I}{N} \\
& =\frac{1462.6}{6} \\
& =243.77 \text { detik }
\end{aligned}
$$

g. Perhitungan waktu normal

Untuk mencari waktu normal tentukan terlebih dahulu faktor penyesuaiannya.

$\mathrm{P}=1-0.02$ 


$$
\begin{aligned}
& =0.98 \\
\mathrm{Wn} & =\mathrm{Ws} \text { X p } \\
& =243.77 \text { X } 0.98 \\
& =238.89 \text { detik }
\end{aligned}
$$

h. Perhitungan waktu baku

$$
\begin{aligned}
\mathrm{Wb} & =\mathrm{Wn}+(1+\ell) \\
\mathrm{Wn} & =238.89 \text { detik } \\
\ell & =0.26 \\
\mathrm{~Wb} & =238.89+(1+0.26) \\
& =240.15 \text { detik }
\end{aligned}
$$

Dari hasil perhitungan di atas, maka didapat nilai rata-rata 243.77 detik, standar deviasi 1.55 detik, standar deviasi rata-rata sub grup 0.63 detik, nilai BKA 245.66 detik, BKB 241.87 detik, N' 0.06, Ws 245.10 detik, Wn 238.89 detik, Wb 240.15 detik.

3. Penggorengan

Dari hasil rekapitulasi data pambuatan kripik tempe pada tahap penggorengan didapat data dalam bentuk sub grup sebagai berikut:

\section{Tabel 8. Perhitungan penggorengan}

\begin{tabular}{|c|c|c|c|c|c|c|c|}
\hline Sub Grup Ke & X1 & X2 & X3 & X4 & X5 & xi & X \\
\hline 1 & 2170 & 2159 & 2163 & 2164 & 2159 & 10815 & 2163 \\
\hline 2 & 2166 & 2165 & 2170 & 2167 & 2164 & 10832 & 2166.4 \\
\hline 3 & 2158 & 2163 & 2168 & 2166 & 2168 & 10823 & 2164.6 \\
\hline 4 & 2164 & 2167 & 2165 & 2158 & 2172 & 10826 & 2165.2 \\
\hline 5 & 2167 & 2169 & 2156 & 2166 & 2165 & 10823 & 2164.6 \\
\hline 6 & 2156 & 2166 & 2159 & 2165 & 2168 & 10814 & 2162.8 \\
\hline \multicolumn{6}{|c|}{ Jumlah } \\
\hline
\end{tabular}

Dari tebel di atas terdapat perhitungan penggorengan yang dibagi menjadi 6 sub grup. Pada sub grup pertama terdapat rata-rata 2163, pada sub grub kedua terdapat rata-rata 2166,4 , pada sub grup ketiga terdapat rata-rata 2164.6 pada sub grub keempat terdapat rata-rata 2165.2, pada sub grub kelima terdapat rata-rata 2164.6, pada sub grub keenam terdapat rata-rata 2162.8 , dengan total waku 12986.6.

Dari data di atas dapat dicari uji kecukupan, uji keseragaman data dan waktu baku dapat dilihat pada langkah-langkah berikut.

a. Perhitungan harga rata-rata dari harga rata-rata sub grup

$$
\begin{aligned}
\bar{\chi}= & \frac{\sum X I}{K} \\
& =\frac{12986.6}{6} \\
& =2164.4
\end{aligned}
$$

b. Menghitung standar deviasi sebenarnya dari waktu penyelesaian

$$
\begin{aligned}
\sigma & =\sqrt{\sum(x i-x)^{2}} \\
& =\frac{4 . x^{6}-1}{4}
\end{aligned}
$$

c. Hitung standar deviasi dari distribusi harga rata-rata sub grup

$$
\begin{aligned}
\sigma \overline{\bar{\chi}} & =\frac{\sigma}{\sqrt{n}} \\
& =\frac{4.26}{\sqrt{6}} \\
& =1.74
\end{aligned}
$$

d. Uji keseragaman data

$$
\begin{aligned}
\mathrm{BKA} & =\overline{\bar{\chi}}+3 \sigma \overline{\bar{\chi}} \\
& =2164.4+3(1.74)
\end{aligned}
$$




$$
\begin{aligned}
& =2169.7 \text { detik } \\
\mathrm{BKB} & =\bar{\chi}-3 \sigma \overline{\bar{\chi}} \\
& =2164.4-3(1.74) \\
& =2159.2 \text { detik }
\end{aligned}
$$

Dari uji keseragaman data di atas pada tahap penggorengan terdapat nilai BKA yaitu 2169.7, BKB 2159.2 dan rata-rata 2164.4.

Dari peta kendali terdapat data diluar batas kendali, maka terdapat beberapa yang harus dihilangkan. BKA sebanyak 1 data yaitu data ke 28 dan BKB sebanyak 4 sata yaitu data ke 3,6,17,21 maka data-data tersebut tidak bisa digunakan untuk uji kecukupan data. Setelah dihilangkan keseluruhan data telah berada di dalam batas kendali dan data dikatakan seragam, sehingga dapat dilanjutkan untuk uji kecukupan data.

e. Uji kecukupan data

Perhitungan uji kecukupan data dapat dilihat sebagai berikut:

$$
\begin{aligned}
N & =\left[\frac{40 \sqrt{N \cdot \sum X I^{2}-\left(\sum X I\right)^{2}}}{\sum X I}\right]^{2} \\
& =0,003
\end{aligned}
$$

Berdasarkan perhitungan di atas, terdapat $\mathrm{N}>\mathrm{N}$ ' maka data dinyatakan cukup.

f. Perhitungan waktu siklus

Perhitungan waktu siklus dapat dilihat sebagai berikut:

$$
\begin{aligned}
\text { WS } & =\frac{\sum X I}{N} \\
& =\frac{12986.6}{6} \\
& =2164.4 \text { detik }
\end{aligned}
$$

g. Perhitungan waktu normal

Untuk mencari waktu normal maka terlebih dulu tentukan faktor penyesuaiannya..

Perhitungan Faktor Penyesuaian sebagai berikut:

$$
\begin{aligned}
\mathrm{P} & =1+0.02 \\
& =1.02
\end{aligned}
$$

Perhitungan waktu normal sebagai berikut:

$\mathrm{Wn}=\mathrm{Ws}$ X P

$$
\begin{aligned}
& =2164.4 \times 1.02 \\
& =2207.68 \text { detik }
\end{aligned}
$$

h. Perhitungan waktu baku

$$
\begin{aligned}
\mathrm{Wb} & =\mathrm{Wn}+(1+\ell) \\
\mathrm{Wn} & =2207.68 \text { detik } \\
\ell & =0.35 \\
\mathrm{~Wb} & =2207.68+(1+0.35) \\
& =2209.04 \text { detik }
\end{aligned}
$$

Dari hasil perhitungan di atas, maka didapat nilai rata-rata 2164.43 detik, standar deviasi 4.26 detik, standar deviasi rata-rata sub grup 1.74 detik, nilai BKA 2169.66 detik, BKB 2159.21 detik, N' 0.0031, Ws 2164.43 detik, Wn 2207.68 detik, Wb 2209.04 detik.

4. Pendinginan

Dari hasil rekapitulasi data pambuatan kripik tempe pada tahap Pendinginan didapat data dalam bentuk sub grup sebagai berikut: 
Tabel 9. Perhitungan pendinginan

\begin{tabular}{|c|c|c|c|c|c|c|c|}
\hline Sub Grup Ke & X1 & X2 & X3 & X4 & X5 & xi & X \\
\hline 1 & 295 & 297 & 295 & 296 & 297 & 1480 & 296 \\
\hline 2 & 289 & 290 & 298 & 297 & 295 & 1469 & 293.8 \\
\hline 3 & 290 & 289 & 289 & 293 & 292 & 1453 & 290.6 \\
\hline 4 & 286 & 285 & 285 & 289 & 296 & 1441 & 288.2 \\
\hline 5 & 288 & 290 & 289 & 288 & 299 & 1454 & 290.8 \\
\hline 6 & 294 & 292 & 285 & 293 & 295 & 1459 & 291.8 \\
\hline \multicolumn{6}{|c|}{ Jumlah } & 8756 & 1751.2 \\
\hline
\end{tabular}

Dari tebel di atas terdapat perhitungan pendinginan yang dibagi menjadi 6 sub grup. Pada sub grup pertama terdapat rata-rata 296, pada sub grub kedua terdapat rata-rata 293.8, pada sub grup ketiga terdapat rata-rata 290.6, pada sub grub keempat terdapat rata-rata 288.2, pada sub grub kelima terdapat rata-rata 290.8, pada sub grub keenam terdapat rata-rata 291,8 dengan total waku 1751.2.

Dari data di atas dapat dicari uji kecukupan, uji keseragaman data dan waktu baku dapat dilihat pada langkah-langkah berikut.

a. Perhitungan harga rata-rata dari harga rata-rata sub grup

$$
\begin{aligned}
\overline{\bar{\chi}} & =\frac{\sum X I}{K} \\
& =\frac{1751.2}{6} \\
& =291.87
\end{aligned}
$$

b. Menghitung standar deviasi sebenarnya dari waktu penyelesaian

$$
\begin{aligned}
\sigma & =\frac{\sqrt{\sum(x i-x)^{2}}}{N-1} \\
& =4.71
\end{aligned}
$$

c. Hitung standar deviasi dari distribusi harga rata-rata sub grup

$$
\begin{aligned}
\sigma \overline{\bar{\chi}} & =\frac{\sigma}{\sqrt{n}} \\
& =\frac{4.71}{\sqrt{6}} \\
& =1.70
\end{aligned}
$$

d. Uji keseragaman data

$$
\begin{aligned}
\mathrm{BKA} & =\bar{\chi}+3 \sigma \overline{\bar{\chi}} \\
& =291.87+3(1.70) \\
& =296.98 \text { detik } \\
\mathrm{BKB} & =\bar{\chi}-3 \sigma \bar{\chi} \\
& =291.87-3(1.70) \\
& =286.75 \text { detik }
\end{aligned}
$$

Dari uji keseragaman data di atas pada tahap pendinginan terdapat nilai BKA yaitu 296.98, BKB 286.75 dan rata-rata 291.87.

Dari peta kendali terdapat data diluar batas kendali, maka terdapat beberapa yang harus dihilangkan. BKA sebanyak 2 data yaitu data ke 14, 29 dan BKB sebanyak 3 sata yaitu data ke 10, 16, 18 maka data-data tersebut tidak bisa digunakan untuk uji kecukupan data. Setelah data dihilangkan keseluruhan data telah berada di dalam batas kendali dan data dikatakan seragam, sehingga dapat dilanjutkan untuk uji kecukupan data.

e. Uji kecukupan data

Perhitungan uji kecukupan data dapat dilihat sebagai berikut:

$$
N=\left[\frac{40 \sqrt{N \cdot \sum X I^{2}-\left(\sum X I\right)^{2}}}{\sum X I}\right]^{2}
$$




$$
=0.20
$$

Berdasarkan perhitungan di atas, terdapat $\mathrm{N}>\mathrm{N}^{\prime}$ maka data dinyatakan cukup.

f. Perhitungan waktu siklus

Perhitungan waktu siklus dapat dilihat sebagai berikut:

$$
\begin{aligned}
\mathrm{WS} & =\frac{\sum X I}{N} \\
& =\frac{1751.2}{6} \\
& =291.87 \text { detik }
\end{aligned}
$$

g. Perhitungan waktu normal

$$
\begin{aligned}
\mathrm{P} & =1+0 \\
& =1 \\
\mathrm{Wn} & =\mathrm{Ws} \text { X } 1 \\
& =291.87 \text { X } 1 \\
& =291.87 \text { detik }
\end{aligned}
$$

h. Perhitungan waktu baku

$$
\begin{aligned}
\mathrm{Wb} & =\mathrm{Wn}+(1+\ell) \\
\mathrm{Wn} & =291.87 \text { detik } \\
\ell \quad & =0.25 \\
\mathrm{~Wb} & =291.87+(1+0.25) \\
& =293.12 \text { detik }
\end{aligned}
$$

Dari hasil perhitungan di atas, maka didapat nilai rata-rata 291.87 detik, standar deviasi 4.17 detik, standar deviasi rata-rata sub grup 1.70 detik, nilai BKA 296.98 detik, BKB 286.75 detik, N'0.20, Ws 291.87 detik, Wn 291.87 detik, Wb 293.12 detik.

\section{Packing}

Dari hasil rekapitulasi data pambuatan kripik tempe pada tahap Packing didapat data dalam bentuk sub grup sebagai berikut:

Tabel 10. Perhitungan Packing

\begin{tabular}{|c|c|c|c|c|c|c|c|}
\hline Sub Grup Ke & X1 & X2 & X3 & X4 & X5 & xi & X \\
\hline 1 & 745 & 743 & 746 & 750 & 746 & 3730 & 746 \\
\hline 2 & 749 & 745 & 748 & 746 & 751 & 3739 & 747.8 \\
\hline 3 & 747 & 749 & 750 & 744 & 745 & 3735 & 747 \\
\hline 4 & 752 & 750 & 746 & 745 & 744 & 3737 & 747.4 \\
\hline 5 & 749 & 748 & 744 & 748 & 749 & 3738 & 747.6 \\
\hline 6 & 747 & 751 & 747 & 749 & 750 & 3744 & 748.8 \\
\hline \multicolumn{7}{|c|}{ Jumlah } \\
\hline
\end{tabular}

Dari tebel di atas terdapat perhitungan packing yang dibagi menjadi 6 sub grup. Pada sub grup pertama terdapat rata-rata 746, pada sub grub kedua terdapat rata-rata 747.8 , pada sub grup ketiga terdapat rata-rata 747., pada sub grub keempat terdapat rata-rata 747.4, pada sub grub kelima terdapat rata-rata 747.6, pada sub grub keenam terdapat rata-rata 748.8, dengan total waku 4484.6.

Dari data di atas dapat dicari uji kecukupan, uji keseragaman data dan waktu baku dapat dilihat pada langkah-langkah berikut.

a. Perhitungan harga rata-rata dari harga rata-rata sub grup

$$
\begin{aligned}
\bar{\chi} & =\frac{\sum X I}{K} \\
& =\frac{4484.6}{6} \\
& =747.43 \text { detik }
\end{aligned}
$$


b. Menghitung standar deviasi sebenarnya dari waktu penyelesaian

$$
\begin{aligned}
\sigma & =\frac{\sqrt{\sum(x i-x)^{2}}}{N-1} \\
& =2.45
\end{aligned}
$$

c. Hitung standar deviasi dari distribusi harga rata-rata sub grup

$$
\begin{aligned}
\sigma \overline{\bar{\chi}} & =\frac{\sigma}{\sqrt{n}} \\
& =\frac{2.45}{\sqrt{6}} \\
& =1
\end{aligned}
$$

d. Uji keseragaman data

$$
\begin{aligned}
\mathrm{BKA} & =\overline{\bar{\chi}}+3 \sigma \overline{\bar{\chi}} \\
& =747.43+3(1) \\
& =750.43 \text { detik } \\
\mathrm{BKB} & =\overline{\bar{\chi}}-3 \sigma \overline{\bar{\chi}} \\
& =747.43-3(1) \\
& =744.44 \text { detik }
\end{aligned}
$$

Dari uji keseragaman data di atas pada tahap packing terdapat nilai BKA yaitu 750.43, BKB 744.44 dan rata-rata 747.43. Dari data di atas terdapat waktu kerja yang diluar batas kendali, sehingga dikatakan tidak seragam.

Dari peta kendali terdapat data diluar batas kendali, maka terdapat beberapa yang harus dihilangkan. BKA sebanyak 4 data yaitu data ke 4, 12, 26 dan BKB sebanyak 1 data yaitu data ke 7, maka data-data tersebut tidak bisa digunakan untuk uji kecukupan data.

Dari peta kendali di atas dapat dilihat bahwa keseluruhan data telah berada di dalam batas kendali dan data dikatakan seragam, sehingga dapat dilanjutkan untuk uji.

e. Uji kecukupan data

Perhitungan uji kecukupan data dapat dilihat sebagai berikut:

$$
\begin{aligned}
N & =\left[\frac{40 \sqrt{N \cdot \sum X I^{2}-\left(\sum X I\right)^{2}}}{\sum X I}\right]^{2} \\
& =0.012
\end{aligned}
$$

Berdasarkan perhitungan di atas, terdapat $\mathrm{N}>\mathrm{N}$ ' maka data dinyatakan cukup

f. Perhitungan waktu siklus

Perhitungan waktu siklus dapat dilihat sebagai berikut:

$$
\begin{aligned}
\mathrm{WS} & =\frac{\sum X I}{N} \\
& =\frac{4484.6}{6} \\
& =747.43 \text { detik }
\end{aligned}
$$

g. Perhitungan waktu normal

$$
\begin{aligned}
\mathrm{P} & =1+0.02 \\
& =1.02
\end{aligned}
$$

Perhitungan waktu normal sebagai berikut:

$$
\begin{aligned}
\mathrm{Wn} & =\mathrm{Ws} \text { X } 1.02 \\
& =747.43 \times 1.02 \\
& =762.38 \text { detik }
\end{aligned}
$$

h. Perhitungan waktu baku 


$$
\begin{aligned}
\mathrm{Wb} & =\mathrm{Wn}+(1+\ell) \\
\mathrm{Wn} & =762.38 \text { detik } \\
\ell & =0.28 \\
\mathrm{~Wb} & =762.38+(1+0.28) \\
& =763.46 \text { detik }
\end{aligned}
$$

Dari hasil perhitungan di atas, maka didapat nilai rata-rata 747.43 detik, standar deviasi 2.45 detik, standar deviasi rata-rata sub grup 1 detik, nilai BKA 750.43 detik,

BKB 744.44 detik, N'0.012, Ws 747.43 detik, Wn 747.43 detik, Wb 763.46 detik.

6. Berdasarkan pengolahan di atas maka didapatkan perbandingan waktu kerja proses sebelum dan sesudah 5S sebagai berikut:

Tabel 11. Perbandingan sebelum dan sesudah penerapan $5 \mathrm{~S}$

\begin{tabular}{|c|l|c|c|}
\hline \multirow{2}{*}{ No } & \multirow{2}{*}{ Nama Stasiun } & \multicolumn{2}{c|}{ Waktu (detik) } \\
\cline { 3 - 4 } & & Sebelum & Sesudah \\
\hline 1 & Pembukaan Bungkus Tempe & 678 & 580.26 \\
\hline 2 & Pengadukan Tepung & 358 & 240.15 \\
\hline 3 & Penggorengan & 2213 & 2209.04 \\
\hline 4 & Pendinginan & 312 & 293.12 \\
\hline 5 & Packing & 779 & 763.46 \\
\hline \multicolumn{2}{|c|}{ Total } & 4340 & 4086.03 \\
\hline
\end{tabular}

Dari tabel di atas dapat dilihat perbedaan waktu sebelum dan sesudah penerapan $5 \mathrm{~S}$ yaitu sebelum di terapkan $5 \mathrm{~S}$ didapat waktu 4340 detik dan setelah diterapkan $5 \mathrm{~S}$ didapat waktu 4086.03 detik,dengan selisih sebanyak 253.97.

\section{SIMPULAN}

Berdasarkan Hasil dan pembahasan didapatkan kesimpulan dari penelitian ini yaitu :

1. Penerapan 5S yang dilakukan di UKM keripik tempe pada penerapan seiri di UKM kripik tempe pada stasiun pengadukan tepung yaitu menyingkirkan barang- barang yang tidak di perlukan. Penerapan seiton di UKM kripik tempe pada stasiun pengadukan tepung yaitu mengatur letak tepung sesuai dengan fungsinya. Penerapan seiso di UKM kripik tempe pada stasiun pembukaan bungkus tempe yaitu menyediakan sarana kebersihan di area kerja. Penerapan Seiketsu menerapkan dan mempertahankan seiri, seiton, dan seiso di stasiun pembukaan bungkus tempe dan pengadukan tepung dengan menjaga kondisi tempat kerja agar tetap rapih dan bersih. Penerapan Shitsuke pada stasiun pembukaan bungkus tempe dan pengadukan tepung yaitu membiasakan untuk menerapkan seiri, seiton, dan seiso dengan melakukan pembersihan setiap selesei bekerja.

2. Waktu kerja proses pembuatan kripik tempe sebelum dilakukannya penerapan $5 \mathrm{~S}$ adalah 4340 detik dan setelah dilakukan penerapan $5 \mathrm{~S}$ waktu yang berbeda yaitu pada tahap pembukaan bungkus tempe 678 detik menjadi 580.26 detik dengan selisih 97.74 detik. Tahap pengadukan tepung 358 detik menjadi 240.15 detik dengan selisih 117.85 detik. Tahap penggorengan 2213 detik menjadi 2209.04 detik dengan selisih 3.96 detik. Tahap pendinginan 312 detik menjadi 293.12 detik dengan selisih 18.88 detik. Tahap packing 779 detik menjadi 763.46 detik dengan selisih 15.54 detik. Selisih total waktu kerja proses adalah 253.97 detik atau 4.23 menit.

\section{DAFTAR PUSTAKA}

Adzim Ilma Hebbie. 2013.Pengertian, Tujuan dan Manfaat Penerapan 5R (5S) di Tempat Kerja https://sistemmanajemenkeselamatankerja.blogspot.com/2013/10/pengertiantujuan-dan-manfaat-penerapan.html.(September 2020). 
Alvina Adini, Hamdani Dany. 2019. Proses Pembuatan Tempe Tradisional..Jurnal Pangan Halal Volume 1 Nomor 1. Universitas Djuanda. Bogor.

Arbi Yaumal, Ernita Tri, Ervil Riko, Marlina Riam, Murad, Wedyawati veni . 2019.Buku Panduan Skripsi. STTIND Padang.

Farihah Tutik, Krisdianti Didik. 2018. Penerapan 5S Pada UKM lahan Makanan di Dusun Sempu, Desa Wonokerto. Jurnal Batik Saintek Volume 2 Nomor 2. UIN Sunan Kalijaga. Yogyakarta.

Kohar, Sulistyadi. 2003. Perancangan Sistem Kerja dan Ergonomi. Universitas Sahid. Jakarta.

Kurniawan Yosi, Sutapa Nyoman. 2018.Perancangan dan Penerapan 5S di Area Hand Add PT Charoen Pokphand Indonesia Feedmill Balaraja. Jurnal Titra, Volume 6 nomor 4.

Pradhana Faried. 2020. Defenisi Pengukuran.https://fariedpradhana.wordpress.com/ (September 2020).

Reza Muhmmad, Azwir Hamdi H. 2019.Penerapan 5S (Seiri, Seiton, Seiso, Seiketsu, Shitsuke) Pada Area Kerja Sebagai Upaya Peningkatan Produktivitas Kerja (Studi Kasus Di CV Widjaya Presisi). Jurnal Teknik Industri, Volume 4 Nomor 2. Fakultas Teknik. Bekasi.

Riko Ervil Silfayona . 2016. Pemanfaatan Turbin Ventilator Dan System Pencahayaan Baru Untuk Meningkatkan Keselamatan Dan Kesehatan Kerja (Studi Kasus IKM Rendamg Kacang). Jurnal Sains dan Teknologi Volume 16 Nomor 1. STTIND. Padang.

Safira Riska, Yustiana Marina, Poeri Pratya. 2017.Penerapan Metode 5S Untuk Meminimasi Waste Motion PadaProses Produksi Rubber Bellow Di Pt Agronesia (Divisi IndustriTeknik Karet). Jurnal Teknik, Volume 4 Nomor 4. Fakultas Teknik Industri, Telkom University. Bandung.

Sutalaksana, Iftikar Z. 2006. Teknik Tata Cara Kerja. Laboratorium Tata Cara Kerja \& Ergonomi, Departemen Teknik Industri ITB. Bandung.

Wahyudi. 2017.Penerapan Budaya Kerja 5SDan Pengaruhnya Terhadap Kinerja Karyawan. Jurnal TeknoterAP, Volume 1 Nomor 1. Fakultas Ekonomi. Sidoarjo.

Wignjosoebroto, Sritomo. 2006 Pengantar Teknik dan Manajemen Industri. Guna Widya. Surabaya. 